\title{
Evolução estrutural e setorial de emprego nas Microrregiões Brasileiras: uma Análise Exploratória para o período 2003- 2013 pelo método shift-share
}

\author{
Thiago Caliari \\ Instituto Tecnológico de Aeronáutica - São José dos Campos - SP - Brasil \\ ORCID: https://orcid.org/0000-0002-6972-0319 \\ Ulisses Pereira dos Santos \\ Universidade Federal de Minas Gerais (UFMG) - Belo Horizonte - MG - Brasil \\ ORCID: https://orcid.org/0000-0002-6912-0479
}

\section{Resumo}

Esse trabalho procurou analisar a evolução do emprego a nível microrregional para o período compreendido entre 2003 e 2013 no Brasil, buscando evidenciar as diferenças microrregionais do período marcado por redução do desemprego a nível nacional, focado principalmente no crescimento da demanda do setor externo, da demanda de camadas inferiores de renda e de investimentos públicos em infraestrutura e habitação. Utiliza-se como suporte a teoria de crescimento econômico e desequilíbrios regionais, bem como evidências empíricas observadas na literatura. A análise é baseada em dados do IBGE e feita através do método shift-share. Os resultados encontrados apresentam redução da desigualdade regional, com crescimento relativo maior para as regiões norte, nordeste e centro-oeste. Os setores que mais contribuíram a nível nacional para esse incremento foram comércio, serviços e construção civil, sendo ainda importantes a administração pública para as regiões Norte e Nordeste e o setor agropecuária, extração vegetal, caça e pesca para a região Centro-oeste. Conclui-se que o padrão de crescimento do emprego pode ter reduzido a desigualdade, mas com especialização em setores de baixo dinamismo e transbordamento setorial.

Palavras-chave: Estrutura do emprego. Microrregiões. Shift-share.

Structural and sectoral evolution of employment in the Brazilian Microregions: An Exploratory Analysis for the period 2003-2013 by the shift-share method

\section{Abstract}

This paper sought to analyze the evolution of employment at the micro-regional level for the period from 2003 to 2013 in Brazil, seeking to observe microregional differences in the period marked by a reduction in national unemployment focused mainly on the growth of external sector demand, the demand of lower income groups and public investments in infrastructure and housing. We use the theory of uneven regional economic development as well as empirical evidences observed in the literature. The analysis is based on IBGE data 
and developed through shift-share method. The results show a reduction in regional inequality, with higher relative growth for the North, Northeast and Midwest regions. The sectors that contributed most to this increase at the national level were trade, services and construction, being important public administration for the North and Northeast regions, as well as the agricultural, logging, hunting and fishing sector for the Midwest region. It can be concluded that the pattern of employment growth may have reduced inequality, but with specialization in both low-dynamic and low-spillover sectors.

Keywords: Employment structure. Microrregions. Shift-share.

\section{Evolución estructural y sectorial del empleo en las microrregiones brasileñas: un análisis exploratorio para el período 2003-2013 por el método shift-share \\ Resumen}

Este trabajo buscó analizar la evolución del empleo a nivel microrregional para el período entre 2003 y 2013 en Brasil, buscando resaltar las diferencias microrregionales del período marcado por la reducción del desempleo a nivel nacional, enfocado principalmente en el crecimiento de la demanda del sector externo, de la demanda. estratos de menores ingresos e inversiones públicas en infraestructura y vivienda. Se utiliza como soporte la teoría del crecimiento económico y los desequilibrios regionales, así como la evidencia empírica observada en la literatura. El análisis se basa en datos del IBGE y se realiza mediante el método shift-share. Los resultados encontrados muestran una reducción de la desigualdad regional, con un mayor crecimiento relativo para las regiones norte, noreste y medio oeste. Los sectores que más contribuyeron a nivel nacional a este incremento fueron el comercio, los servicios y la construcción civil, siendo la administración pública aún importante para las regiones Norte y Nordeste y el sector agrícola, extracción de plantas, caza y pesca para la región Medio Oeste. Se concluye que el patrón de crecimiento del empleo puede haber reducido la desigualdad, pero con especialización en sectores con bajo dinamismo y desbordamiento sectorial.

Palabras clave: Estructura de empleo, microrregiones, Shift-share.

\section{Introdução}

Segundo dados do Instituto de Pesquisa Econômica Aplicada (IPEA)', a taxa de desemprego no Brasil passou de 14,1\% em 2003 para 7,8\% em 2013, sendo esse processo pautado por uma ampliação no grau de formalização do trabalho no país (REMY, QUEIROZ e FILHO, 2011). Essa importante redução, observada depois de um período de oscilações macroeconômicas, vem sendo estudada e debatida dentro da academia brasileira. Em suma, a explicação que é premente parte (i) do ciclo de valorização das commodities no mercado internacional (SESSA, SIMONATO e DOMINGUES, 2017) - com o aumento da demanda asiática, principalmente na China -, (ii) do aumento da demanda interna fruto das políticas de distribuição de renda do governo - através do acesso aos mercados por uma faixa da população que antes se posicionava em condições críticas de pobreza - (SILVEIRA NETO e AZZONI, 2013) e (iii) do financiamento estatal em projetos de infraestrutura e habitacionais, representados principalmente nos Programas de Aceleração do Crescimento (PAC 1 em 2007 e PAC 2 em 2010), na Política de Desenvolvimento Produtivo (PDP em 2008) e no Plano Brasil Maior (PBM em 2011).

\footnotetext{
${ }^{1}$ Informações disponíveis em http://www.ipeadata.gov.br/Default.aspx. Acesso em 21/09/2019.
} 
Tais questões levaram a um crescimento médio do PIB de 3,56\% a.a. no período de 2003 a 2013, com resultados no desenvolvimento econômico em relação à estabilidade de preços, distribuição de renda e inclusão social (CURADO, 2011). Porém, nesse ínterim, indagações e críticas têm sido levantadas sobre a impossibilidade desse crescimento ser sustentável a longo prazo, dado questões relacionadas à doença holandesa (BRESSER-PEREIRA, 2008), à desindustrialização (OREIRO e FEIJÓ, 2010) e aos limites do padrão de crescimento via demanda. Julgase parte desse período - os anos do governo Lula - até como um 'nacionaldesenvolvimentismo às avessas' (GONÇALVES, 2012) ou um embate entre convenções distintas de desenvolvimento (estabilizadora e neodesenvolvimentista) (ERBER, 2011).

Uma questão que ascende nesse cenário diz respeito aos impactos regionais do supracitado ciclo de crescimento. Ou seja, questiona-se se tal processo foi capaz de contribuir ou não para a redução da desigualdade regional que caracteriza a economia brasileira. Considera-se, portanto, a necessidade de se observar e avaliar os problemas relacionados ao desenvolvimento regional desigual no Brasil perante ao recente ciclo de crescimento pelo qual passou a economia nacional. O período de análise é marcado por políticas com esse objetivo.

Em 2003 foi lançada a Política Nacional de Desenvolvimento Regional (PNDR I), revigorado em 2012 (PNDR II) (RESENDE et al., 2015), e em conjunção a essa política, outras a nível federal (como programas de universalização e regionalização do ensino superior), estadual e municipal foram praticadas (complementares ou não) com vistas a buscar a redução da desigualdade. Dentre os resultados esperados para esse processo, se destacariam o aumento da oferta de trabalho qualificado e a consequente ampliação da massa salarial. Ainda, o formato de atuação de algumas políticas federais horizontais - notadamente o Bolsa Família teve o perfil de impactar em maior escala nas regiões menos favorecidas, sendo, portanto, um vetor importante de redução de desigualdades (SILVEIRA NETO e AZZONI, 2013).

No entanto, é no emprego que se verifica um importante vetor para a redução da desigualdade, pois é a remuneração do fator trabalho que se apresenta como a principal fonte de renda de populações menos favorecidas. Porém, 0 incremento do trabalho e renda não deve ser visto como um fim único; esse fim não pode ser desprovido de um aparato que o sustente e permita sua evolução contínua e sustentada. Antes disso, a evolução da capacitação econômica de uma região deve ser vista como um conjunto de ações, políticas, instituições e atores que permitam, ao longo do tempo, um desenvolvimento resiliente baseado no aumento da produtividade dos setores econômicos (MYRDAL, 1960; PERROUX, 1967; LIMA, 2006; AMARAL FILHO, 2001).

Isso posto, o objetivo desse trabalho é fazer uma análise exploratória da evolução do emprego a nível microrregional no Brasil, destacando a evolução do período 2003-2013. A escolha do período de análise recai sobre o contexto político e econômico. Politicamente, o período retrata a emergência de um governo de centro-esquerda, capitaneado pelo Partido dos Trabalhadores (PT) nas figuras de Luís Inácio Lula da Silva (2003-2010) e Dilma Rousseff (2011-2016). Define-se, porém, o limite temporal de 2013 para expurgar da análise os efeitos da crise econômica 
brasileira que se inicia em 2015 (ainda no governo de Dilma Rousseff), mas que já apresenta sinais em 2014 (CARVALHO, 2018).

Em suma, procuramos responder a seguinte pergunta: como se observa a evolução da composição setorial microrregional de emprego no Brasil? Para responder essa indagação será utilizada a metodologia shift-share para microrregiões brasileiras, com composição setorial definida por classificação IBGE. A análise pretende ser exploratória, com o intuito de captar a evolução do emprego e os principais vetores setoriais responsáveis pela evolução das capacidades econômicas, mas não se abstendo de dirimir opiniões relacionadas à capacitação regional para o desenvolvimento de longo prazo. Assim, uma segunda pergunta que se mostra premente é: a evolução do emprego é sustentável para o desenvolvimento econômico de longo prazo, considerando a importância da evolução do dinamismo das atividades econômicas?

A busca de respostas para essas perguntas se dará à luz das mudanças estruturais e regionais na economia brasileira ao longo das últimas décadas. Nesse sentido, é destacável o processo de relocalização da indústria no território do país, intensificado ao longo da década de 1990 e mantido ao longo da década de 2000, sem, contudo, diminuir o protagonismo da região Sudeste (DINIZ, 1993; SABOIA, 2013). Outro aspecto a ser considerado é o processo de redução da importância relativa da indústria de transformação para o conjunto da indústria nacional. Observa-se ao longo das últimas décadas (1990, 2000 e 2010) uma redução do peso do setor para os principais indicadores conjunturais analisáveis, como o emprego, o PIB e as exportações setoriais (CANO, 2012; MORCEIRO, 2018).

Deve-se verificar, portanto, dois fenômenos relacionados à indústria que ocorrem concomitantemente e que apresentam grandes impactos sobre a estrutura do emprego regional no Brasil: a redução da representatividade do setor e a sua reorientação locacional. Perante a esses processos, a literatura aponta para o aumento da importância do setor de serviços nos grandes centros urbanos do país (SABOIA, 2013), além dos setores primários (produção agrícola e extrativa mineral) em todo o território nacional (CANO, 2012). Nesse sentido, a avaliação das mudanças na estrutura do emprego para o conjunto da economia brasileira, na observação a nível regional, deve tangenciar essa série de fenômenos recentes, contribuindo para o entendimento dos mesmos.

Esse trabalho está dividido em 5 seções, a contar essa introdução. A segunda seção apresenta o referencial teórico adotado por esse trabalho, o qual se sustenta basicamente nas teorias do desenvolvimento regional desequilibrado. Na terceira seção são apresentados indicadores agregados por setor, com vistas a aprofundar o entendimento da dinâmica nacional de emprego, bem como a remuneração e demais variáveis. Na seção 4 são discutidos os resultados obtidos pelo método shiftshare para as microrregiões, fechando a análise com as considerações finais na quinta seção do trabalho.

\section{Crescimento econômico e desequilíbrios regionais}

É fato que o crescimento econômico não é igualmente distribuído no espaço, condição essa que leva à identificação de polos ou pontos onde este apresenta maior intensidade em relação às demais regiões em um determinado território 
nacional (HIRSCHMAN, 1977). Nesse sentido, o crescimento econômico regional demonstra um caráter desequilibrado, conduzindo à difusão de desigualdades entre diferentes localidades em um mesmo país, tendo essa condição ascendido como o ponto de partida para desenvolvimentos teórico-conceituais no campo da economia regional ao longo do século XX (LIMA, 2006).

As principais interpretações para essa condição ascenderam nas décadas de 1950 e 1960, com base nas contribuições de autores como Perroux (1967), Hirschman (1977) e Myrdal (1965). O primeiro construiu sua teoria dos polos de crescimento, segundo a qual o crescimento das regióes seria dinamizado pela existência de uma indústria motriz, a qual espalharia seu crescimento interno, fruto de sua atividade inovativa, por meio de seus encadeamentos envolvendo fornecedores e compradores. Entre outros aspectos, esta teoria explica a tendência à aglomeração de atividades econômicas interligadas e o papel de empresas líderes no contexto regional (DINIZ, 2001). De acordo com o que é proposto na teoria dos polos de crescimento, regiões dotadas de uma indústria motriz, ou fortemente conectadas a ela por meio de uma cadeia de produção, tenderiam a crescer de forma intensa. $O$ estímulo inicial para o crescimento da indústria motriz e de regiões em seu entorno seria a sua própria atividade de inovação (LIMA, 2006; LIMA e SIMÕES, 2010).

Já as contribuições de Hirschman (1977) e Myrdal (1965), amplamente reconhecidas como teorias do crescimento regional desequilibrado, tiveram como principais focos de análise as diferenças no ritmo de crescimento das regiões internas a um mesmo ambiente nacional (DINIZ, 2001). Nesse sentido, assumia-se a possibilidade de que o crescimento econômico manifestado em algumas regióes específicas poderia gerar transbordamentos sobre as outras regiões que também se beneficiariam desta situação (HIRSCHMAN, 1977). Tais transbordamentos se materializariam por meio dos efeitos de encadeamento para frente (forward effects) ou para trás (backward effects), sendo estes sustentados por meio de relações de mercado envolvendo empresas estabelecidas nas regiões compreendidas por tal fenômeno (LIMA e SIMÕES, 2010).

Cabe destacar que essa perspectiva assume tanto a existência de efeitos positivos quanto negativos do crescimento das regiões mais dinâmicas sobre as regiões menos desenvolvidas. Nesse sentido, dado o caráter desequilibrado do crescimento econômico regional, se os impactos positivos da expansão das regiões mais dinâmicas sobre economias menos desenvolvidas prevalecessem, estas se beneficiariam desta situação por meio dos efeitos de fluência. Nesse sentido, os efeitos de fluência fazem com que o crescimento de uma determinada região estimule crescimento em outras regiões vizinhas. Por sua vez, uma situação oposta, em que prevalecessem os efeitos negativos do crescimento de uma região sobre as demais, leva a um quadro em que as disparidades entre as regiões podem ser ampliadas. Em tal condição prevaleceriam os efeitos de polarização.

A partir dos efeitos de polarização, as regiões com maior nível de crescimento tenderiam a reter para si os ganhos do progresso, ampliando sua distância em relação às demais localidades. Como consequência, as regiões já desenvolvidas ampliariam a sua riqueza ao longo do tempo enquanto as menos desenvolvidas teriam sua estagnação perpetuada, seguindo uma tendência de cumulatividade (MYRDAL, 1965). Nesse sentido, as regiões dotadas de melhor 
infraestrutura e aparato produtivo mais avançado tenderiam a apresentar maior nível de crescimento que a média nacional. Tal crescimento traria condições para que essas regiões reforçassem seu nível de investimento interno ampliando ainda mais as condições para a continuidade de seu crescimento.

Por sua vez, as regiões menos desenvolvidas, em razão do baixo nível de crescimento, apresentariam menores condições para melhorar sua infraestrutura interna ou estimular o setor produtivo interno. Tal processo ocorreria baseado em uma série de movimentos que se realimentariam a partir de uma lógica circular de fortalecimento da concentração regional da renda (MYRDAL, 1965). Seria estabelecido, assim, um tipo de ciclo vicioso em que regiões dinâmicas tendem a manter e ampliar seu dinamismo, por serem mais propensas ao crescimento, enquanto regiões pobres tendem a se manter nessa condição (LIMA e SIMÕES, 2010). Logo, o simples fato de uma região mais dinâmica concentrar os setores mais ativos da economia a levaria a gozar de condições diferenciadas, como uma maior massa salarial, maiores lucros e maior arrecadação tributária.

Da mesma forma, a prévia existência de quadros profissionais de maior qualificação, revertida em maiores salários, faria com que nas regiões mais dinâmicas também se concentrassem o consumo e, consequentemente, mercados mais dinâmicos. Entende-se, deste modo, que as regiões mais ativas economicamente teriam maiores condições de sustentar e ampliar seu próprio crescimento, em contraposição ao que ocorre nas regiões menos desenvolvidas. Nessas condições, tais regiões tenderiam a se manter em condição de estagnação. Isso resultaria, segundo a lógica dos efeitos de polarização, de um movimento natural tanto do investimento privado como do investimento estatal em favor das regiões com melhor histórico de crescimento (LIMA e SIMÕES, 2010).

As teorias dos polos e do desenvolvimento regional desequilibrado mantiveram forte influência sobre a economia e política regional até o final do século XX, fornecendo conceitos para desenvolvimentos teóricos recentes. Nesse sentido, para explicar a concentração industrial conceitos como o de causação circular foram associados a conceitos anteriormente ligados à tradição neoclássica da economia regional, como o estudo dos custos de transportes no âmbito da Nova Geografia Econômica (AMARAL FILHO, 2001; LIMA, 2006).

\section{Emprego e renda no Brasil - evolução dos indicadores agregados por setor}

Como uma primeira observação para o entendimento da evolução da dinâmica evolutiva do emprego nacional, apresenta-se abaixo uma evolução dos indicadores agregados através do recorte setorial do Instituto Brasileiro de Geografia e Estatística (IBGE) definida em oito rubricas, a saber: '1. extrativa mineral', '2. indústria de transformação', '3. serviços industriais de utilidade pública', '4. construção civil', '5. comércio', '6. serviços', '7. administração pública' e '8. agropecuária, extração vegetal, caça e pesca'. Os dados foram obtidos no sítio da Relação Anual de Informações Sociais disponibilizada pelo Ministério do Trabalho e Emprego (Rais-MTE). Como informações iniciais são apresentadas a evolução do emprego e remuneração do trabalho para o conjunto dos dados nacionais, seguindo o período compreendido entre 2003 e 2013. 
A primeira informação (Tabela 1) apresenta a evolução do emprego setorial no total de empregos e número de empregos por setor IBGE. Conforme pode ser depreendido, o setor 'serviços' é o maior empregador da economia brasileira, apresentando um aumento da participação no total de emprego de 31,7\% em 2003 para $34,2 \%$ em 2013. O setor apresenta ainda um incremento de $78,3 \%$ no total de empregados no período, maior que a média geral de $65,7 \%$. Este dado indica a continuidade de uma das mudanças mais importantes na estrutura do emprego no brasil ao longo das últimas décadas, que pode ter sido diretamente impactado entre 2003 e 2013 pelo quadro de liberalização comercial, iniciado ainda na década de 1990, e pela apreciação cambial observada nesse período (CANO, 2012; PAULI, NAKABASHI e SAMPAIO, 2012).

Os demais setores que aumentaram sua participação no total de empregos foram 'comércio' (17,3\% para 19,4\%), 'construção civil' (3,6\% para 5,9\%) e 'extrativa mineral' ( $0,4 \%$ para $0,5 \%)$, todos frutos do aumento acima da média no número de empregados, sendo reflexo do impulso econômico desses setores na economia brasileira durante o período considerado. No caso do setor 'comércio', o incremento no emprego pode ser atrelado ao modelo de crescimento adotado no Brasil, especialmente a partir de 2007 , com base no incentivo ao crescimento da demanda interna por meio de estímulos ao consumo (políticas de renda e crédito). Como resultado, esse setor foi o principal responsável pelo crescimento econômico brasileiro ao longo do período aqui avaliado (JACINTO e RIBEIRO, 2015). O setor 'construção civil' também se beneficiou de programas de governo, com foco em segmentos como habitação e infraestrutura, enquanto o setor 'extrativa mineral' foi diretamente impactado pelo aquecimento da demanda internacional por commodities e pela consequente melhora nos preços externos (SESSA, SIMONATO e DOMINGUES, 2017).

Tabela 1 - Total de Empregos por setor IBGE (2003-2013)

\begin{tabular}{c|c|c|c|c|c|c|c|c|c}
\hline Anos & $\begin{array}{c}\text { Extrativa } \\
\text { Mineral }\end{array}$ & $\begin{array}{c}\text { Indústria } \\
\text { transform. }\end{array}$ & $\begin{array}{c}\text { Serv } \\
\text { industriais }\end{array}$ & $\begin{array}{c}\text { Const } \\
\text { Civil }\end{array}$ & Comércio & Serviços & $\begin{array}{c}\text { Admin. } \\
\text { Pública }\end{array}$ & $\begin{array}{c}\text { Agrop, } \\
\text { ext } \\
\text { vegetal, } \\
\text { caça e } \\
\text { pesca }\end{array}$ & Total \\
\hline 2003 & 122.806 & 5.356 .159 & 319.068 & 1.048 .251 & 5.119 .479 & 9.378 .566 & 6.991 .973 & 1.207 .670 & 29.543 .972 \\
2005 & 147.560 & 6.133 .461 & 341.989 & 1.245 .395 & 6.005 .187 & 10.510 .761 & 7.543 .939 & 1.310 .320 & 33.238 .612 \\
2007 & 185.444 & 7.082 .167 & 364.665 & 1.617 .989 & 6.840 .915 & 11.935 .780 & 8.198 .396 & 1.382 .070 & 37.607 .426 \\
2009 & 208.836 & 7.361 .084 & 385.379 & 2.132 .288 & 7.692 .951 & 13.235 .389 & 8.763 .970 & 1.427 .649 & 41.207 .546 \\
2011 & 231.389 & 8.113 .805 & 412.741 & 2.750 .173 & 8.842 .677 & 15.372 .455 & 9.103 .601 & 1.483 .790 & 46.310 .631 \\
2013 & 261.383 & 8.292 .739 & 444.674 & 2.892 .557 & 9.511 .094 & 16.726 .013 & 9.340 .409 & 1.479 .564 & 48.948 .433 \\
\hline $\begin{array}{c}\Delta \text { total } \\
(2013 / 2003)\end{array}$ & $112,8 \%$ & $54,8 \%$ & $39,4 \%$ & $175,9 \%$ & $85,8 \%$ & $78,3 \%$ & $33,6 \%$ & $22,5 \%$ & $65,7 \%$ \\
\hline
\end{tabular}

Fonte: Elaboração própria.

É importante destacar também que a rubrica 'comércio' passa a ser o segundo maior setor em número de empregados em 2013, com queda de participação da 'administração pública (23,7\% para 19,1\%); conjuntamente, 'comércio' e 'serviços' respondiam em 2013 pelo total de 53,6\% da mão-de-obra formal empregada no Brasil. O aumento da representatividade do setor comércio em 
termos de emprego deve ser observada com certa dose de ceticismo, uma vez que se trata de um setor de baixa produtividade do trabalho, convertida em baixa remuneração individual (JACINTO e RIBEIRO, 2015).

O setor 'indústria de transformação' apresenta declínio na participação total de empregos, um indicador de um processo de desindustrialização (ROWTHORN e RAMASWAMY, 1998), apesar do aumento de pessoal empregado. Cabe destacar que há um movimento de queda de participação do emprego industrial observado desde o início da década de 1990, movimento também seguido no valor da produção e na participação nas exportações nacionais (CANO 2012; PAULI, NAKABASHI e SAMPAIO, 2012; MORCEIRO, 2018). Fatores como a liberalização comercial, a sobrevalorização cambial e as altas taxas de juros domésticas com a consequente redução do investimento industrial estariam associados a essa perda de representatividade da indústria de transformação na composição geral do emprego formal no país.

Adicionalmente, apresenta-se abaixo a evolução do salário médio real dos trabalhadores. As séries de salário médio tiveram os valores deflacionados para reais de 2015 com o uso do Índice de Preços ao Consumidor Amplo (IPCA-IBGE), disponível no sítio do IPEADATA.

Figura 1 - Evolução do Salário Real - média Setores IBGE (R\$ de 2015)

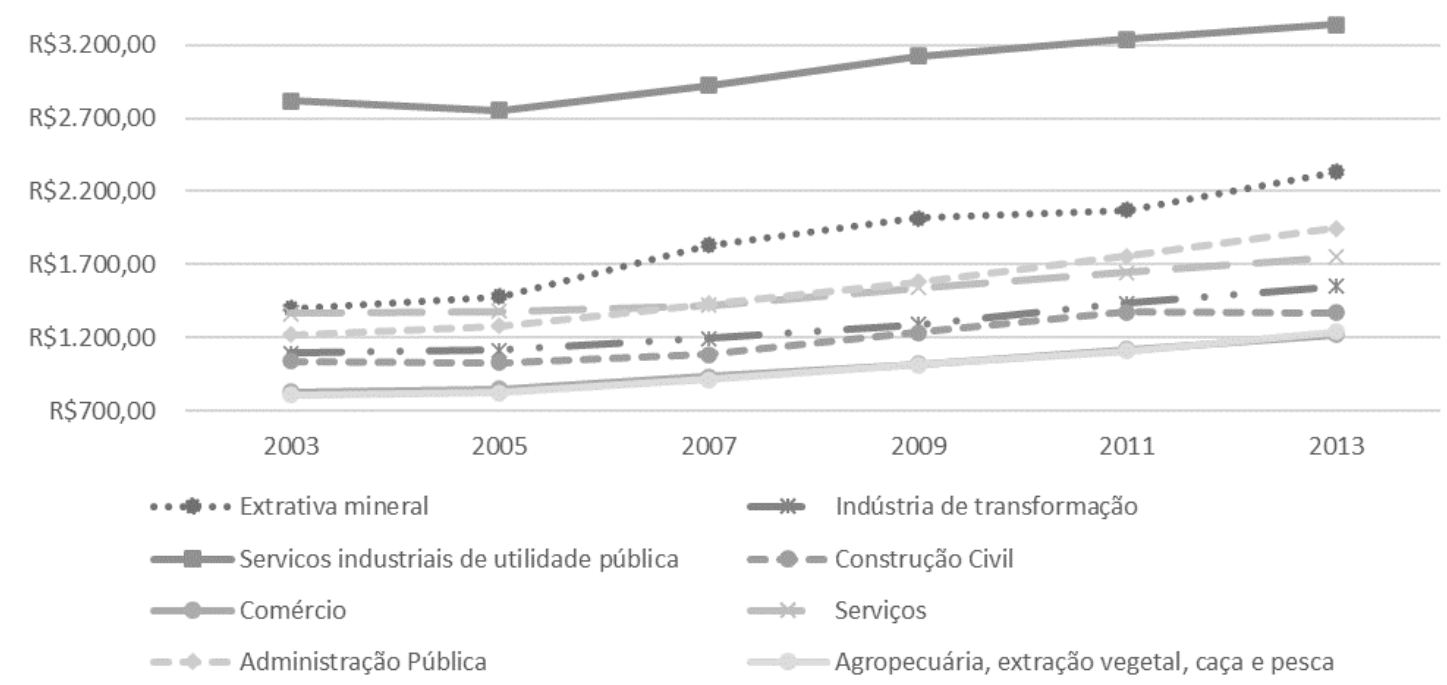

Fonte: Elaboração própria.

Em suma, o aumento real dos salários para todos os setores sofre impacto da política de valorização do salário mínimo. Esse impacto também pode ser mensurado pelo aumento da participação da remuneração via salário no PIB nacional, que passou de 36,1\% em 2005 para 45\% em 2013 (FILHO e PAULA, 2016). A remuneração média do setor IBGE 'serviços industriais de utilidade pública' foi durante todo o período superior a todos os demais setores, mas foi também a que teve menor percentual de aumento do salário real (18,5\%). Mesmo assim, ainda manteve uma diferença da ordem de $43 \%$ em relação à remuneração real média do segundo setor ('extrativa mineral'). 
Além disso, um crescimento considerável da rubrica 'extrativa mineral' e a mudança de posicionamento entre 'administração pública' e 'serviços' pode ser destacada. No caso da indústria extrativa mineral, há que se salientar a demanda por trabalho qualificado (técnico e superior) e a alta produtividade do setor no Brasil, que permitem compreender como seu crescimento resultou em progressos consideráveis em termos de remuneração (JACINTO e RIBEIRO, 2015). Para a administração pública, a demanda por trabalho qualificado também é um elemento explicativo para a evolução das remunerações.

Uma observação importante da análise conjunta da evolução da quantidade de empregos e do salário real médio se relaciona ao fato de o aumento da participação da mão-de-obra empregada em comércio e serviços ser seguida por um crescimento real menor dos salários nessas rubricas. $O$ 'comércio' apresenta 0 menor salário real médio em 2013 ( $R \$ 1220,87$ ), e o setor serviços apresenta a segunda menor taxa de crescimento (28,3\%). Este aspecto pode ser creditado à baixa produtividade do setor de comércio e em boa parte dos subsetores que compõem a rubrica serviços no Brasil' (ARBACHE, 2015). Destaca-se que esse resultado ocorre a despeito do setor 'serviços' ter se notabilizado pelo aumento no emprego de trabalhadores com formação superior nos últimos anos (PAULI, NAKABASHI e SAMPAIO, 2012).

Ainda, além da política de valorização do salário mínimo, o aumento observado do salário real deve ser analisado em conjunção à modificação no perfil educacional dos trabalhadores, expresso pela variação da proporção de trabalhadores com ensino superior, mestrado e doutorado. Essas informações são apresentadas na Tabela 2.

O período de análise não é compatível porque a desagregação da escolaridade na RAIS-MTE só é disponibilizada para dados a partir de 2006, mas mesmo assim pode-se observar uma relação entre o incremento de salário real e da proporção de trabalhadores com maior escolaridade. No próprio caso da classificação 'serviços industriais de utilidade pública', o menor incremento de salário real se apresenta associado ao menor incremento na escolaridade dos trabalhadores.

Os valores observados para essas informações iniciais do agregado da economia brasileira apontam para um quadro que tem sido bastante discutido no ambiente acadêmico. Suas principais características são: (i) a evolução dos salários acima da inflação (consagrado pelos sucessivos aumentos reais do salário mínimo e seu impacto na economia); (ii) o aumento da importância dos setores de 'construção civil', 'comércio' e 'serviços' em detrimento do seu baixo dinamismo econômico, expresso em aumentos menores dos salários reais; (iii) o aumento da proporção de trabalhadores com ensino superior, mestrado e doutorado, que tem estreita ligação com as políticas de acesso ao ensino superior estabelecidas nos governos Lula (2003-2010) e Dilma (2010-2016) (PINHO e ZAN, 2013; BRASIL, 2015).

\footnotetext{
2 Jacinto e Ribeiro (2015) mostram que a produtividade dos serviços cresceu durante o período 20002009, pautado principalmente em serviços às empresas. Porém, serviços especializados e que tem perfil de maior produtividade (P\&D; Projetos; consultorias; financeiros) são menos representativos no país como um todo.
} 
Tabela 2 - Número de trabalhadores total; Número de trabalhadores com ensino superior, mestrado e doutorado

\begin{tabular}{|c|c|c|c|c|c|c|c|c|}
\hline \multirow[b]{2}{*}{ Setores IBGE } & \multicolumn{3}{|c|}{2006} & \multicolumn{3}{|c|}{2013} & \multirow[b]{2}{*}{$\begin{array}{c}\text { Variação \% } \\
\text { trabalhadores } \\
\text { com ensino } \\
\text { superior, } \\
\text { mestrado e } \\
\text { doutorado } \\
(2006-2013)\end{array}$} & \multirow[b]{2}{*}{$\begin{array}{l}\text { Variação } \\
\text { no } \\
\text { salário } \\
\text { real } \\
(2003- \\
2013)\end{array}$} \\
\hline & $\begin{array}{l}\text { superior, } \\
\text { mestrado } \\
\text { e } \\
\text { doutorado } \\
\text { (1) }\end{array}$ & Total (2) & $\begin{array}{l}(1) / \\
(2)\end{array}$ & $\begin{array}{l}\text { superior, } \\
\text { mestrado } \\
\text { e } \\
\text { doutorado } \\
\text { (3) }\end{array}$ & Total (4) & $\begin{array}{l}\text { (3)/ } \\
\text { (4) }\end{array}$ & & \\
\hline Extrativa mineral & 28.570 & 183.188 & $15,6 \%$ & 57.089 & 261.383 & $21,8 \%$ & $40,0 \%$ & $67,1 \%$ \\
\hline $\begin{array}{l}\text { Indústria de } \\
\text { transformação }\end{array}$ & 394.734 & 6.594 .783 & $6,0 \%$ & 716.467 & 8.292 .739 & $8,6 \%$ & $44,3 \%$ & $41,9 \%$ \\
\hline $\begin{array}{l}\text { Serviços } \\
\text { industriais de } \\
\text { utilidade pública } \\
\end{array}$ & 55.635 & 344.563 & $16,1 \%$ & 81.981 & 444.674 & $18,4 \%$ & $14,2 \%$ & $18,5 \%$ \\
\hline Construção Civil & $55 \cdot 301$ & 1.393 .446 & $4,0 \%$ & 145.210 & 2.892 .557 & $5,0 \%$ & $26,5 \%$ & $42,8 \%$ \\
\hline Comércio & 266.268 & 6.330 .337 & $4,2 \%$ & 566.687 & 9.511 .094 & $6,0 \%$ & $41,7 \%$ & $47,2 \%$ \\
\hline Serviços & 1.990 .620 & 11.229 .881 & $17,7 \%$ & 3.518 .566 & 16.726 .013 & $21,0 \%$ & $18,7 \%$ & $28,3 \%$ \\
\hline $\begin{array}{l}\text { Administração } \\
\text { Pública }\end{array}$ & 2.451 .836 & 7.721 .815 & $31,8 \%$ & $3 \cdot 916.519$ & 9.340 .409 & $41,9 \%$ & $32,1 \%$ & $60,0 \%$ \\
\hline $\begin{array}{l}\text { Agropecuária, } \\
\text { extração vegetal, } \\
\text { caça e pesca }\end{array}$ & 23.642 & 1.357 .230 & $1,7 \%$ & 44.181 & 1.479 .564 & $3,0 \%$ & $71,4 \%$ & $53,2 \%$ \\
\hline Total & 5.266 .606 & 35.155 .243 & $15,0 \%$ & 9.046 .700 & 48.948 .433 & $18,5 \%$ & $23,4 \%$ & $48,7 \%$ \\
\hline
\end{tabular}

Fonte: elaboração própria.

Todavia, para o presente trabalho essa discussão preliminar deve servir como um 'pano de fundo' para um contexto mais específico, buscando uma análise microrregional da evolução do emprego, o que será feito nas próximas seções.

\section{A evolução do emprego nas microrregiões brasileiras a partir do método shift- share}

\subsection{Fonte de dados e o método shift-share}

Os dados utilizados foram obtidos no sítio da Relação Anual de Informações Sociais disponibilizada pelo Ministério do Trabalho e Emprego (Rais-MTE) e classificados segundo o recorte setorial do Instituto Brasileiro de Geografia e Estatística (IBGE) definido em oito rubricas, a saber: '1. extrativa mineral', '2. indústria de transformação', '3. serviços industriais de utilidade pública', '4. construção civil', '5. comércio', '6. serviços', '7. administração pública' e '8. agropecuária, extração vegetal, caça e pesca’.

Para analisar a evolução do emprego nas microrregiões brasileiras optou-se nesse trabalho pela análise da estrutura setorial de emprego através do método shift-share (SIMÕES, 2005), inserindo o aperfeiçoamento proposto por EstebanMarquillas (1972). Especificamente, o método pretende identificar e desagregar os componentes do crescimento do emprego em uma análise descritiva da estrutura econômica por componentes que destacam (i) o dinamismo setorial na criação de empregos (efeito estrutural - EE), resultante da sua composição estrutural com 
setores que cresceram mais do que na média nacional; (ii) as (des)vantagens locacionais (efeito diferencial - D), sendo que o valor positivo (negativo) que a região j alcançará é em razão da taxa de crescimento em determinado(s) setor(es) ser maior (menor) nesta região do que na média nacional; (iii) a observação da especialização regional em setores que possuem maior vantagem competitiva (efeito alocação - A).

Da soma desses três efeitos tem-se a Variação Líquida Total (VLT), que indica o montante líquido de emprego que determinada microrregião obteve entre o ano inicial e final da análise. As equações para cada componente seguem conforme especificação abaixo.

$V L T=E E+D+A$

$V L T=E_{i j}^{0}\left(e_{i}-e\right)+\left(2 E_{i j}^{0}-E_{i j}^{0 *}-E_{i j}^{t}+E_{i j}^{t *}\right)\left(e_{i j}-e_{i}\right)+\left(E_{i j}^{t}-E_{i j}^{t *}-E_{i j}^{0}+E_{i j}^{0 *}\right)\left(e_{i j}-e_{i}\right)$

Em que:

$E_{i j}^{0}=$ emprego do setor $i$ da região $j$ no ano base (2003);

$E_{i j}^{t}=$ emprego do setor $i$ da região $j$ no ano final (2013);

$e=$ taxa de crescimento do emprego nacional;

$e_{i}=$ taxa nacional de crescimento do emprego no setor $i$

$e_{i j}=$ taxa de crescimento do emprego no setor $i$ na região $j ;$

$E_{i j}^{(0 / t) *}=$ emprego esperado ou homotético no ano base/final, dado pela expressão:

$E_{i j}^{(0 / t) *}=E_{j}^{(0 / t)}\left(E_{i}^{(0 / t)} / E^{(0 / t)}\right)$

Sendo:

$E_{j}^{(0 / t)}=$ emprego total da região $j$ no ano base/final;

$E_{i}^{(0 / t)}=$ emprego total do setor $i$ no ano base/final;

$E^{(0 / t)}=$ emprego total nacional no ano base/final.

Se o VLT é negativo, há perda líquida de emprego durante os períodos; se positivo, o contrário é verdadeiro. Os anos de comparação da análise serão os anos de 2003 e 2013, considerando as 558 microrregiões do território brasileiro.

Catorze resultados distintos são possíveis a partir da consideração da VLT, considerando as distintas combinações dos efeitos EE, D e A. O extremo satisfatório da análise corresponde ao caso que apresenta resultados positivos para os três componentes da classificação da estrutura setorial. Nesse caso, pode-se considerar que a microrregião cresceu pelo dinamismo da estrutura setorial e incrementou suas vantagens locacionais, mas não há uma definição exata ainda sobre os resultados do efeito alocação, visto que uma microrregião pode ter valor positivo desse efeito se for especializada em setores com rápido crescimento $(++++)$ ou não especializada em setores pouco competitivos ( - - = +) (ESTEBAN-MARQUILLAS, 1972). Um tratamento específico considerando apenas o caso de vantagem 
competitiva especializada será utilizado para contornar esse problema quando feitas as análises.

Nossa análise não será baseada sobre os quatorze possíveis resultados (desses quatorze, doze são encontrados no uso da técnica, o que torna a comparação bastante complicada para o tamanho do artigo). Ao invés disso vamos adotar o critério de análise dos VLTs por quartis positivos e negativos, incluindo 3 quartis para VLTs negativos e 3 quartis para VLTs positivos (utilizaremos essa classificação para fazer comparações sobre emprego, renda e demais variáveis socioeconômicas) e análise dos efeitos estrutural, diferencial e alocação com vantagem competitiva especializada em cada microrregião.

\subsection{Resultados do método shift-share}

Como primeira informação apresentamos a tabela abaixo com a distribuição por classificação dos resultados VLT.

Em linhas gerais, verifica-se que a maioria das microrregiões brasileiras (58,2\%) apresentaram resultados de VLT positivos no período considerado; justamente por esse motivo os grupos com microrregiões que tiveram VLT positivo são maiores (grupos 4 a 6). Na observação das cinco regiões (Sul, Sudeste, CentroOeste, Nordeste e Norte), diferença significativa é verificada nos valores percentuais de VLTs. As regiões Norte e Centro-oeste são as que mais possuem microrregiões com VLT positivo, com resultados bastante superiores às demais. Em menor escala, mas ainda acima da média, pode-se verificar que os resultados comparativos também são válidos em favor da região Nordeste, que possuiu $68,1 \%$ das microrregiões com VLT positivo.

Tabela 3 - Classificação VLT e Regiões Federativas

\begin{tabular}{l|c|c|c|c|c|c}
\hline \multirow{2}{*}{ Valores VLT } & \multirow{2}{*}{ Frequência } & \multicolumn{5}{c}{ Região Federativa } \\
\cline { 4 - 7 } & & N & NE & SE & S & CO \\
\hline Grupo 1 (-408620.7 a -5010.4) & 78 & & 13 & 41 & 22 & 2 \\
\hline Grupo 2 (-5005.5 a -1314.9) & 78 & 4 & 14 & 32 & 26 & 2 \\
\hline Grupo 3 (-1293.5 a 0) & 77 & 5 & 33 & 24 & 12 & 3 \\
\hline Grupo 4 (0 a 1550.2) & 109 & 16 & 52 & 19 & 8 & 14 \\
\hline Grupo 5 (1659.9 a 4772.1) & 108 & 19 & 43 & 21 & 12 & 13 \\
\hline Grupo 6 (4849.8 a 97720.2) & 108 & 20 & 33 & 23 & 14 & 18 \\
\hline Total & 558 & 64 & 188 & 160 & 94 & 52 \\
\hline \% VLT Positivo & & $85.9 \%$ & $68.1 \%$ & $39.4 \%$ & $36.2 \%$ & $86.5 \%$ \\
\hline \% VLT Negativo & & $14.1 \%$ & $31.9 \%$ & $60.6 \%$ & $63.8 \%$ & $13.5 \%$ \\
\hline
\end{tabular}

Fonte: Elaboração própria.

Em um contexto ainda bastante geral, um primeiro resultado verificado pelo método diferencial-estrutural é o ganho comparativo de empregos em favor de regiões do interior do território nacional. Esse resultado está em acordo com 
estudos referentes às décadas de 1990 e 2000, especialmente para o emprego industrial (CANO, 2012; DINIZ, 1993).

A Tabela 4 apresenta informações sobre emprego, renda, variáveis socioeconômicas e educacionais, com resultados interessantes em relação às disparidades entre os grupos. Em relação à remuneração média, os grupos extremos - grupos 1 e 6 - possuem os maiores valores tanto em 2003 quanto em 2013. O crescimento de grupos intermediários - grupos 3, 4 e 5 - é, porém, maior, o que permite incorrer sobre uma diminuição nas disparidades médias salariais. Essa observação é interessante se comparada à população média dessas microrregiões. Novamente, observa-se populações médias maiores nos extremos dos grupos, sendo os demais compatíveis com valores muito próximos de média. A consideração conjunta desses resultados permite salientar uma diminuição da disparidade em escala regional, com incrementos maiores de salário para microrregiões de menor escala populacional e econômica, o que está alinhado à perspectiva teórica dos efeitos de fluência (HIRSCHMAN, 1977; LIMA e SIMÕES, 2010).

Tabela 4 - Variáveis selecionadas segundo Grupo VLT

\begin{tabular}{|c|c|c|c|c|c|c|c|c|}
\hline Variáveis & Anos & Grupo 1 & Grupo 2 & Grupo 3 & Grupo 4 & Grupo 5 & Grupo 6 & Total \\
\hline \multirow{2}{*}{ Remun. Média ( $\mathrm{R} \$$ ) } & 2003 & 1,407 & 1,168 & 923 & 920 & 992 & 1,28 & 1,107 \\
\hline & 2013 & 1,864 & 1,662 & 1,463 & 1,472 & 1,55 & 1,876 & 1,645 \\
\hline$\Delta$ Remun. Média (\%) & & $32.51 \%$ & $42.32 \%$ & $58.62 \%$ & $60.02 \%$ & $56.22 \%$ & $46.58 \%$ & $48.69 \%$ \\
\hline \multirow{2}{*}{ Média empregados } & 2003 & 196,407 & 27,493 & 14,537 & 15,634 & 15,167 & 70,927 & 53,021 \\
\hline & 2013 & 298,753 & 42,751 & 23,463 & 26,89 & 27,993 & 135,421 & 87,856 \\
\hline $\begin{array}{l}\Delta \text { Média } \\
\text { empregados (\%) }\end{array}$ & & $52.11 \%$ & $55.50 \%$ & $61.40 \%$ & $72.00 \%$ & $84.57 \%$ & $90.93 \%$ & $65.70 \%$ \\
\hline \multirow{2}{*}{ População } & 2003 & 847,721 & 199,178 & 145,861 & 142,574 & 167,647 & 463,95 & 316,564 \\
\hline & 2013 & 954,186 & 219,429 & 158,393 & 161,355 & 190,196 & 554,42 & 361,549 \\
\hline$\Delta$ População (\%) & & $12.56 \%$ & $10.17 \%$ & $8.59 \%$ & $13.17 \%$ & $13.45 \%$ & $19.50 \%$ & $14.21 \%$ \\
\hline \multirow{2}{*}{ PIB (milhares R\$) } & 2003 & 22,1 & 3,442 & 1,503 & 1,801 & 1,896 & 8,074 & $6,063,580$ \\
\hline & 2013 & 35,9 & 5,973 & 2,491 & 3,509 & 3,499 & 16,4 & $10,700,000$ \\
\hline$\Delta \mathrm{PIB}(\%)$ & & $62.44 \%$ & $73.56 \%$ & $65.70 \%$ & $94.77 \%$ & $84.54 \%$ & $103.11 \%$ & $76.46 \%$ \\
\hline \multirow{2}{*}{ PIB per capita ( $R \$$ ) } & 2003 & 19,678 & 15,563 & 10,012 & 9,819 & 11,356 & 17,568 & 13,824 \\
\hline & 2013 & 28,085 & 22,917 & 15,343 & 17,921 & 17,839 & 29,97 & 22,001 \\
\hline$\Delta$ PIB per capita (\%) & & $42.73 \%$ & $47.25 \%$ & $53.24 \%$ & $82.51 \%$ & $57.09 \%$ & $70.59 \%$ & $59.15 \%$ \\
\hline \multirow{2}{*}{$\begin{array}{l}\text { \% da população com } \\
\text { ensino superior ou } \\
\text { acima }\end{array}$} & 2003 & 0.109 & 0.100 & 0.097 & 0.095 & 0.086 & 0.100 & 0.097 \\
\hline & 2013 & 0.142 & 0.144 & 0.162 & 0.168 & 0.150 & 0.147 & 0.153 \\
\hline $\begin{array}{l}\Delta \text { Ensino Superior ou } \\
\text { acima (\%) }\end{array}$ & & $30.63 \%$ & $43.77 \%$ & $65.86 \%$ & $76.84 \%$ & $75.22 \%$ & $47.15 \%$ & $57.14 \%$ \\
\hline
\end{tabular}

Fonte: Elaboração própria.

O grupo 1 está associado a um perfil de cidades maiores, com diminuição comparativa de seu tamanho econômico visto o menor crescimento dos salários, empregos, PIB e PIB per capita em relação aos demais grupos. São regiões que já possuem escala econômica relevante e entram, possivelmente, em um horizonte de deseconomias urbanas (já que tais regiões apresentam em média valores negativos elevados de efeito diferencial - média de -38792.5 -, este associado às desvantagens locacionais) (DINIZ, 1993). Para esse conjunto de regiões, elementos 
como o custo da terra, impostos e custos trabalhistas podem figurar como entraves para um maior nível de crescimento econômico ao longo do tempo (LEMOS, 1988). O grupo 2 parece abarcar um conjunto de cidades medianas - aproximadamente 220 mil habitantes em 2013 - que apresenta um menor crescimento das capacidades econômicas e de sua população. Esse resultado também é válido para o Grupo 3, mas com um perfil de tamanho um pouco menor - 158 mil habitantes.

Comparativamente, esses três grupos apresentam um padrão de crescimento do emprego menor que as demais regiões, e esses resultados também são válidos para o crescimento das demais variáveis comparadas (com exceção de remuneração e acesso ao ensino superior para o Grupo 3, acima da média nacional).

Nos grupos 4 e 5 encontramos microrregiões com porte populacional próximo às microrregiões do grupo 3 , mas que obtiveram crescimento maior no número de empregados, no PIB e no PIB per capita (e por isso mesmo se diferenciaram, possuindo VLT positivo). No grupo 6 temos microrregiões de porte médio a grande, com população de aproximadamente 555 mil habitantes em 2013, e que obtiveram os maiores crescimentos em número de empregados, população e PIB, mas não em PIB per capita, remuneração média e acesso ao ensino superior. São regiões, portanto, que cresceram fortemente em valores totais, mas que não apresentaram os melhores resultados em valores relativos.

A Tabela 5 abaixo busca captar, na média, os principais determinantes para os resultados dos VLTs dos grupos considerados. Como pode se depreender, os resultados são bastante distintos e, para alguns efeitos, bastante próximos em grupos com VLTs muito distintos. Tomamos o cuidado de incluir em uma coluna alternativa os resultados médios por grupo apenas para o efeito alocação vantagem competitiva especializada $(++=+)$, considerando apenas os setores em que as microrregiões são especializadas e que cresceram acima da média nacional.

Tabela 5 - Valores médios VLT, EE, D, A e Vantagem Competitiva Especializada, segundo Grupo VLT

\begin{tabular}{c|c|c|c|c|c}
\hline Grupos & $\begin{array}{c}\text { Efeito } \\
\text { estrutural } \\
\text { (EE) }\end{array}$ & $\begin{array}{c}\text { Efeito } \\
\text { diferencial } \\
\text { (D) }\end{array}$ & $\begin{array}{c}\text { Efeito } \\
\text { alocação (A) } \\
\text { total }\end{array}$ & VLT & $\begin{array}{c}\text { Efeito Alocação } \\
\text { Vantagem } \\
\text { Competitiva } \\
\text { especializada }\end{array}$ \\
\hline 1 & 3337.5 & -38792.5 & 8698.5 & -26756.6 & 3646.7 \\
2 & -1379.3 & -24273.8 & 22868.8 & -2802.6 & 22096.3 \\
3 & -979.5 & -2247.3 & 2590.4 & -636.4 & 2190.7 \\
4 & -573.6 & -1101.7 & 2380.2 & 704.9 & 2939.6 \\
5 & -861.4 & -6220.6 & 9943.6 & 2861.6 & 12237.2 \\
6 & 724.5 & -43780.1 & 61247.8 & 18179.0 & 66602.0 \\
\hline
\end{tabular}

Fonte: Elaboração própria.

Observa-se que o efeito estrutural é positivo apenas para os grupos 1 e 6 . Isso significa que, na média, as microrregiões que tiveram os VLTs no extremo positivo e no extremo negativo têm composição setorial com maior peso dos setores que mais crescem na média nacional. Os resultados para essas regiões 
continuam a ser próximos quando comparados os valores para o efeito diferencial, que destacam as vantagens locacionais regionais. Nesse caso, as microrregióes possuem valores negativos altos, o que indica uma composição interna com setores que crescem abaixo da média nacional (ou seja, apesar de ter uma composição setorial que cresce muito na média nacional, internamente tem crescido pouco nessas regiões).

O que as diferencia de maneira clara é o efeito alocação; nesse caso, o ganho das microrregiões do grupo 6 é maior na comparação nacional, o que permitiu que tais localidades pudessem se posicionar no extremo superior do $\mathrm{VLT}^{3}$. É interessante verificar que para o conjunto total das médias dos grupos o efeito diferencial tem valores negativos e o efeito alocação tem valores positivos. Isso não significa, porém, que todas as microrregiões seguiram a média; na contagem total, 225 microrregiões tiveram efeito diferencial positivo e 101 microrregiões tiveram efeito alocação negativo. Mesmo assim, um padrão é passível de destaque: a maioria das microrregiões tem setores crescendo abaixo da média nacional (considerando o efeito diferencial negativo para 333 microrregiões, 59,7\% do total).

Há de se destacar também a comparação entre o efeito alocação total e efeito alocação competitiva especializada: caso o último seja maior que o primeiro, significa que foi importante para elevar a média total (e, portanto, apresentou maior importância que a desvantagem competitiva não especializada). O contrário também é verdadeiro. Notadamente, a definição vantagem competitiva especializada teve impacto forte no efeito alocação total dos grupos com VLT positivo, sendo o contrário para os demais grupos.

Uma análise microrregional dos setores que mais contribuíram para o VLT positivo - Figura 2 - mostra que os mais relevantes são o setor comércio, que tem o maior VLT positivo em 33,5\% das microrregiões (187) e o segundo maior VLT positivo em outras 38,2\% (213) das microrregiões. É seguido pelo setor serviços, que responde por ter o primeiro VLT positivo em 19,7\% (110) e o segundo VLT positivo em 19,4\% (108) microrregiões, pelo setor construção civil $\left(16,7 \%\right.$ e 11,0\%) ${ }^{4}$, indústria de transformação (12,0\% e 15,1\%), administração pública (5,0\% e 11,8\%), agropecuária, extração vegetal, caça e pesca (4,8\% e 3,2\%), extrativa mineral (6,3\% e 0,9\%) e serviços industrias de utilidade pública (1,8\% e 0,5\%).

\footnotetext{
${ }^{3}$ Apesar das microrregiões do grupo 1 também alcançarem efeito alocação positivo, não foi suficiente para dirimir o valor negativo do efeito diferencial.

${ }^{4}$ A hierarquização setorial foi estabelecida considerando o primeiro e segundo valor positivo do VLT. Utilizaremos essa ordem também na comparação para os demais efeitos.
} 
Figura 2 - Setores com maior variação positiva no VLT - microrregiões

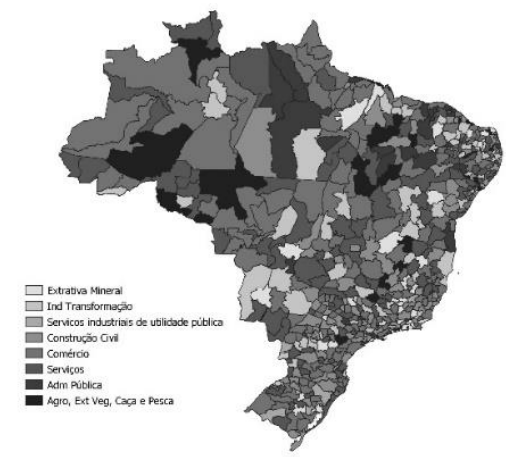

2a. Primeiro Setor

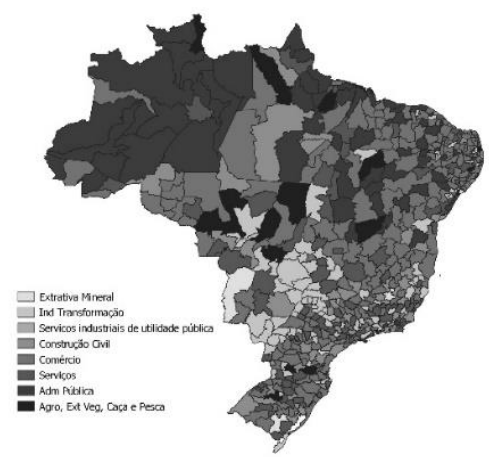

2b. Segundo Setor

Fonte: Elaboração própria.

A análise detalhada dos principais setores com valor positivo para cada efeito do método diferencial/estrutural pode ser importante para uma observação mais minuciosa do impacto desses setores nas microrregiões comparadas. 0 primeiro efeito analisado na Figura 3 - efeito estrutural (EE) - mostra que os setores com maior variação positiva são comércio (63,8\% e $23,5 \%)$, construção civil $(22,9 \%$ e $20,6 \%$ ), serviços (11,1\% e 53,1\%) e extrativa mineral (2,1\% e 2,9\%). Reconsiderando, vale relembrar que o efeito estrutural é positivo quando a microrregião é especializada em setores da economia nacional que apresentam altas taxas de crescimento, acima da média nacional.

$O$ resultado mostra que o efeito estrutural segue em linha com 0 crescimento desses setores no total nacional - conforme explicitado na Figura $1 \mathrm{e}$ Tabela 1 -, com participação principal do setor comércio que, apesar de não ser o setor com maior crescimento percentual no total de emprego nacional, foi o principal setor responsável pelo efeito estrutural positivo na maioria das microrregiões brasileiras.

Figura 3 - Setores com maior variação positiva no Efeito Estrutural (EE) microrregiões

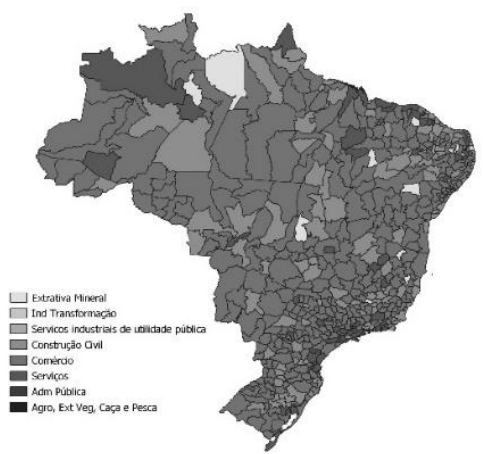

3a. Primeiro Setor Fonte: Elaboração própria.

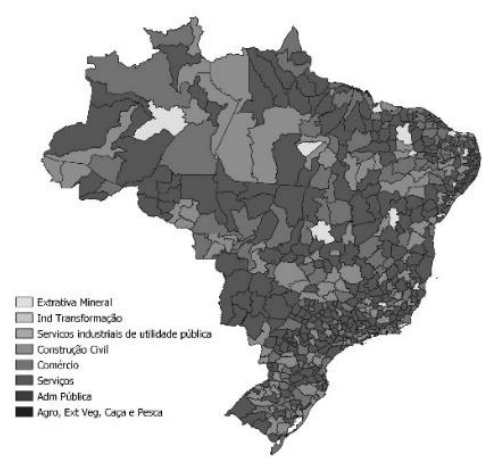

3b. Segundo setor 
$\mathrm{Na}$ análise do efeito diferencial (Figura 4), cabe destacar que os setores apresentaram a seguinte ordem de importância: serviços (35,5\% e 10,8\%), indústria de transformação (18,6\% e 18,5\%), construção civil (17,4\% e 9,5\%), administração pública (15,1\% e 25,1\%), comércio (9,9\% e 21,5\%), agropecuária, extração vegetal, caça e pesca (1,6\% e $5,7 \%)$, extrativa mineral $(1,1 \%$ e $4,8 \%)$ e serviços industriais de utilidade pública $(0,9 \%$ e $4,1 \%)$.

Figura 4. Setores com maior variação positiva no Efeito Diferencial (D) microrregiões

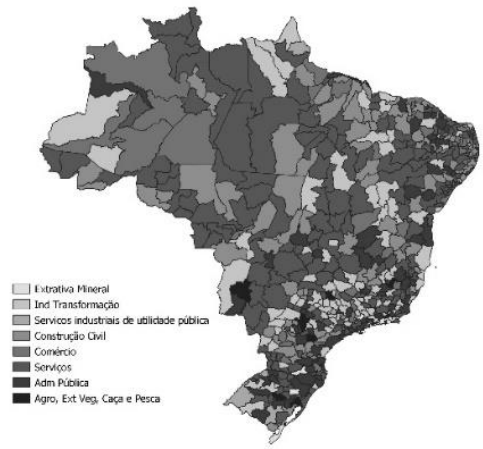

4a. Primeiro Setor Fonte: Elaboração própria.

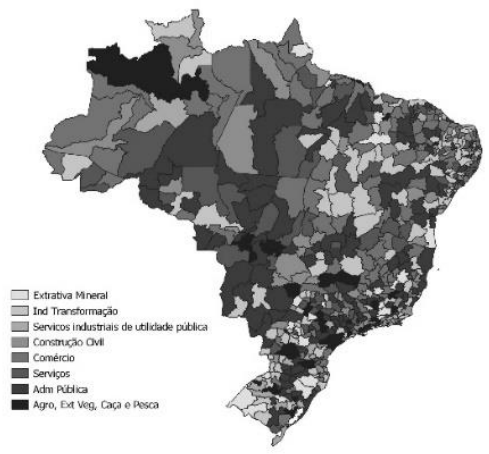

4b. Segundo setor

Nota-se ainda que resultados consistentes em favor de determinados setores não são tão claros na análise do efeito diferencial quanto na análise do efeito estrutural, mas existem padrões diferenciados de relevância setorial que são passíveis de destaque quando analisadas regiões federativas. Considerando a soma do percentual de cada setor como primeiro ou segundo setor na variação positiva e analisando quais setores tiveram percentual por região federativa acima da média nacional, observam-se os seguintes comportamentos:

1. extrativa mineral: sudeste e sul;

2. indústria de transformação: sudeste e sul;

3. serviços industriais de utilidade pública: sul

4. construção civil: norte, nordeste e centro-oeste;

5. comércio: norte e nordeste

6. serviços: norte, nordeste e centro-oeste;

7. administração pública: sul, sudeste e centro-oeste;

8. agropecuária, extração vegetal, caça e pesca: sul, sudeste e centro-oeste.

Como já explicitado, o componente diferencial indica o crescimento da microrregião pelo fato da taxa de crescimento em determinados setores ter sido maior nela do que na média nacional do mesmo setor. Sendo assim, nota-se a relevância de serviços, comércio e construção civil para o desenvolvimento do emprego principalmente no norte e nordeste, justamente os setores de principal crescimento e com grande nível de participação no emprego nacional.

Por último, apresentam-se os mapas nacionais para a análise do efeito alocação, no que tange especificamente ao efeito 'vantagem competitiva 
especializada'; ou seja, no mapa são representados os setores que apresentaram valor positivo para a rubrica especialização e para a rubrica vantagem competitiva (considera-se apenas o efeito de setores para os quais as microrregiões possuem especialização e vantagem competitiva quando comparadas à média nacional). Por conta disso, algumas microrregiões aparecem sem nenhuma representação na Figura 7. É importante salientar que as regiões com menor número de microrregiões sem efeito alocação vantagem competitiva especializada positivo foram as regiões Norte, Nordeste e Centro-oeste.

Os resultados para o primeiro setor com variação positiva são relevantes nos casos comparativos de algumas regiões. Por exemplo, o setor agropecuária, extração vegetal, caça e pesca foi responsável pelo estabelecimento do efeito em grande parte da região Centro-oeste, com importância elevada também para o oeste mineiro e nas porções sudoeste da região Nordeste, na Bahia principalmente. Esses resultados estão relacionados ao boom de commodities no mercado internacional (SESSA, SIMONATO e DOMINGUES, 2017), em específico ao impacto do aumento da fronteira agrícola da soja no Brasil (FREDERICO, 2013).

Figura 5 - Setores com maior variação positiva no Efeito Alocação (A) - Vantagem Competitiva Especializada - microrregiões

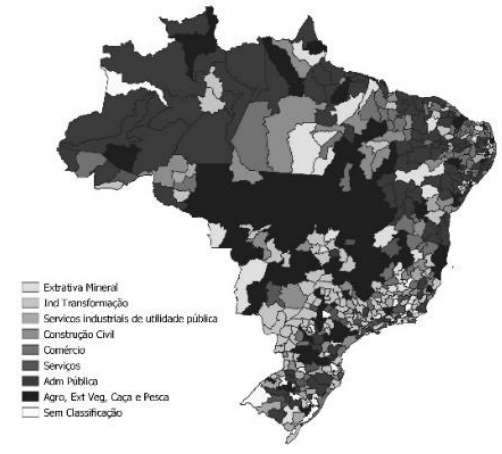

5a. Primeiro Setor

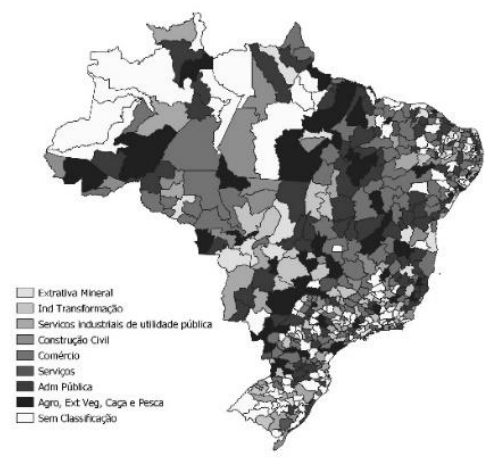

5b. Segundo setor

Fonte: Elaboração própria.

Ainda, um grupo de microrregiões localizadas no sul da região Centro-oeste - principalmente no Mato Grosso do Sul -, no norte do Paraná, no oeste paulista e no triângulo e sul de Minas Gerais apresentam resultados favoráveis para a indústria de transformação. Esses resultados devem estar linkados também à fronteira agrícola da soja e ao papel destacado da indústria alimentícia e de suporte às atividades agrícolas.

A administração pública apresenta relevância para as regiões Norte e Nordeste, destacando o efeito do aumento do aparato público como um importante definidor do aumento do emprego nessas regiões. Esse aumento deve estar associado às políticas de acesso à educação superior, que elevou o número de instituições federais de ensino principalmente nessas regiões, mas não deve ser visto como o único componente desse processo. De qualquer forma, maiores estudos são importantes para a análise desse aspecto, o que pode ser feito em futuros trabalhos. 


\section{Considerações finais}

Esse trabalho procurou observar a evolução do emprego setorial nas microrregiões brasileiras no período 2003-2013, considerando para tal recorte o componente político (a emergência de um governo dito de centro-esquerda) e econômico, marcado por um processo, a nível nacional, de redução do desemprego e resultados macroeconômicos importantes no que diz respeito a crescimento - PIB - e desenvolvimento econômico - PIB per capita. Apesar disso, é um período entendido por vieses bastante distintos, visto que a base do crescimento foi focada em um comportamento exógeno - a demanda internacional por produtos de baixa intensidade tecnológica, as commodities -, um padrão interno de crescimento orientado pela demanda via políticas de redistribuição de renda e pelo financiamento estatal em projetos de infraestrutura e habitacionais. Associado a isso, uma política de valorização do salário mínimo promoveu um aumento real da remuneração média durante todo o período.

Os impactos desse processo de crescimento ficam claros no aumento na participação do emprego do setor comércio e construção civil e no declínio do setor indústria de transformação, o que é aderente à evolução da estrutura já observada em trabalhos anteriores (CANO, 2012; SABOIA, 2013; MORCEIRO, 2018). O problema é que essa modificação da estrutura setorial de emprego é impactada diretamente também pelo perfil salarial dos setores; o setor comércio apresenta o menor salário real médio em 2013, o setor construção civil o terceiro menor, e o setor serviços apresenta a segunda menor taxa de crescimento (esse o setor de maior empregabilidade na economia nacional). Em suma, tais observações apontam para uma especialização da economia nacional em setores com baixa produtividade do trabalho, o que destoa das teorias regionais que destacam a importância do aumento da produtividade para o dinamismo econômico (LIMA, 2006).

$\mathrm{Na}$ análise desenvolvida através do método shift-share, é verificado um resultado satisfatório para o total das microrregiões nacionais com maior número de microrregiões apresentado resultado de VLT positivo. Considerando as regiões federativas, importante resultado também é obtido quando observado que as regiões norte, nordeste e centro-oeste possuem comparativamente mais microrregiões com VLT positivo, o que indica uma redução da disparidade regional no emprego em comparação às regiões mais desenvolvidas do país, as regiões sul e sudeste. Nesse sentido, é possível dizer que predominaram efeitos de fluência ao longo desse período em detrimento de efeitos de polarização (HIRSCHMAN, 1977; MYRDAL, 1957; LIMA e SIMÕES, 2010).

Nesse sentido, as observações para esse contexto microrregional permitem concluir que existe um comportamento de redução de desigualdade de remuneração pelo porte populacional e econômico, com um maior crescimento da remuneração média em cidades pequenas e médias. Ressalta-se que algumas cidades de médio porte - de 150 a 550 mil habitantes - se destacaram como as principais beneficiadas da evolução estrutural do emprego no período considerado.

A observação dos distintos efeitos dos componentes do VLT nos mostrou diferentes resultados setoriais. Em resumo, os setores que mais contribuíram para o VLT positivo foram o setor comércio, com ampla vantagem, seguido de serviços e construção civil, tendo os mesmos a maior frequência no efeito estrutural e efeito 
diferencial. Cabe destacar que os resultados são congruentes com os encontrados para período anterior (1991-2003) por Sesso Filho et al (2010), demonstrando ser uma tendência com horizonte temporal maior do que o período compreendido nesse artigo.

Ainda, para o efeito alocação com vantagem competitiva especializada, notamos a relevância do setor administração pública para as regiões Norte e Nordeste, do setor agropecuária, extração vegetal, caça e pesca na região Centrooeste, no oeste mineiro e nas porções sudoeste da região Nordeste (Bahia principalmente), resultado este conectado ao boom das commodities, em específico à expansão da fronteira agrícola da soja, e indústrias de transformação no sul da região Centro-oeste, no norte do Paraná, no oeste paulista e no triângulo e sul de Minas Gerais, resultados esses conexos ao papel destacado da indústria alimentícia e de suporte às atividades agrícolas.

Pode-se desses resultados depreender sobre algumas características específicas do processo de desenvolvimento econômico observado no período analisado. De um lado, refletem ganhos no que tange à diminuição da desigualdade regional com o aumento relativo do número de empregos nas regiões Norte, Nordeste e Centro-oeste, contribuindo para a redução de desequilíbrios regionais. Por outro lado, tal processo de desenvolvimento pode ser passivo de críticas, considerando que as bases da diminuição do desemprego foram calcadas em setores com baixo dinamismo econômico, que não envolvem transbordamentos setoriais e com baixa agregação de valor (PERROUX, 1967; LIMA, 2006). Nessa mesma linha, a redução da representatividade do emprego industrial é um elemento importante para a análise desse processo, uma vez que a indústria é um segmento fundamental para a promoção dos transbordamentos supracitados (PERROUX, 1967; CANO, 2012; MORCEIRO, 2018).

As políticas públicas parecem ter sido importantes nesse processo de redução de desequilíbrio regional. Os programas de infraestrutura e habitação promoveram inclusão social, e o aumento do acesso ao ensino superior caminha junto a esse resultado. Contudo, não parecem apresentar articulação com as necessidades locais, estando mais conectadas à estratégia nacional.

\section{REFERÊNCIAS}

AMARAL FILHO, J. A endogeneização no desenvolvimento econômico regional e local. Planejamento e Políticas Públicas, 23: 261-86, 2001.

ARBACHE, J. Produtividade no setor de serviços. In DE NEGRI, F.; CAVALCANTE, L. R. (Orgs.). Produtividade no Brasil: desempenho e determinantes. Brasília, IPEA, pp. 277-300, 2015.

BRASIL. A democratização e expansão da educação superior no Brasil: 2003-2014, Brasília, Ministério da Educação, 2015.

BRESSER-PEREIRA, L. C. The Dutch disease and its neutralization: a Ricardian approach. Brazilian Journal of Political Economy, 28(1), 47-71, 2008. 
CANO, W. A desindustrialização no Brasil. Economia e Sociedade, 21(4), 831-851, 2012.

CARVALHO, L. Valsa Brasileira: do boom ao caos econômico. São Paulo: Todavia, 2018.

CURADO, M. Uma avaliação da economia brasileira no Governo Lula. Economia \& Tecnologia, Volume Esp(Ano 07), 91-104, 2011.

DINIZ, C. C. Desenvolvimento poligonal no Brasil: nem desconcentração, nem contínua polarização. Nova Economia, 3(1), 35-64, 1993.

DINIZ, C. C. O Papel das Inovações e das Instituições no Desenvolvimento Local. In Anais XXIX Encontro Nacional de Economia (pp. 1-21). Salvador, 2001.

ERBER, F. S. As convenções de desenvolvimento no governo lula: um ensaio de economia política. Revista de Economia Política, 31(1), 31-55, 2011.

ESTEBAN-MARQUILLAS, J. M. A reinterpretation of Shift-share Analysis. Regional and Urban Economics, 2(3), 249-261, 1972.

FILHO, F. F., PAULA, L. F. Padrões de crescimento e desenvolvimentismo: uma perspectiva keynesiano-institucionalista. Nova Economia, 26(3), 775-807, 2016.

FREDERICO, S. Agricultura científica globalizada e fronteira agrícola moderna no Brasil. Confins (Online), 17, 2013.

GONÇALVES, R. Governo Lula e o nacional- desenvolvimentismo às avessas. Soc Bras Economia Politica, 31, 5-30, 2012.

HAUSMANN, R., HIDALGO, C. A., BUSTOS. S., COSCIA, M., CHUNG, S., JIMENEZ, J., MUHAMMED, A. Y. The Atlas of Economic Complexity. (Harvard \& MIT, Eds.), Mapping Paths to Prosperity, 2011.

HIRSCHMAN, A. Transmissão Inter-regional e Internacional do Crescimento Econômico. In SCHWARTZMAN, J. (Org.), Economia Regional: textos escolhidos. Belo Horizonte: CEDEPLAR-UFMG, pp. 35-52, 1977.

JACINTO, P. A., RIBEIRO, E. P. Crescimento Da Produtividade No Setor De Serviços E Da Indústria No Brasil: Dinâmica E Heterogeneidade. Economia Aplicada, 401-427, 2015.

KALDOR, N. A Model of Economic Growth. The Economic Journal, 67(268), 591-624, 1957. 
LEMOS, M. B. Espaço e capital um estudo sobre a dinâmica centro-periferia. Universidade Estadual de Campinas, 1988.

LIMA, A. C. A Teoria do Desenvolvimento Regional e o papel do Estado. Análise Econômica, 24/45: 65-90, 2006.

LIMA, A. C., SIMÕES, R. Teorias Clássicas do Desenvolvimento Regional e suas Implicações de Política Econômica: o Caso do Brasil. RDE - Revista de Desenvolvimento Econômico, 21: 5-20, 2010.

MARINHO, E. L. L., NOGUEIRA, C. A. G., ROSA, A. L. T. Evidências Empíricas da Lei de Kaldor-Verdoorn para a Indústria de Transformação do Brasil (1985-1997). Revista Brasileira de Economia, 56(3), 457-482, 2002.

MORCEIRO, P. C. A indústria brasileira no limiar do século XXI: uma análise da sua evolução estrutural, comercial e tecnológica. São Paulo: USP, 2018.

MORRONE, H. Estimação da Lei de Kaldor- Estimação da Lei de Kaldor-Verdoorn para a indústr Verdoorn para a indústr Verdoorn para a indústria brasileira no período 2001-12. Indic. Econ. FEE, 41(1), 75-86, 2013.

MYRDAL, G. Economic Theory and Underdeveloped Regions. London: Gerald Duckworth, 1957.

MYRDAL, G. Teoria econômica e regiões subdesenvolvidas. Belo Horizonte: Editora UFMG, 1960.

MYRDAL, G. Teoria Econômica e Regiões Subdesenvolvidas. Rio de Janeiro: Editora Saga, 1965.

OREIRO, J. L., FEIJÓ, C. A. Desindustrialização: conceituação, causas, efeitos e o caso brasileiro. Revista de Economia Política, 30(2), 219-232, 2010.

PAULI, R. C. DE, NAKABASHI, L., SAMPAIO, A. V. Mudança estrutural e mercado de trabalho no Brasil. Revista de Economia Política, 32(3), 459-478, 2012.

PERROUX, F. A Economia do Século XX. Lisboa: Livraria Morais, 1967.

PINHO, I. R., ZAN, D. D. P. Plano nacional de Educação (PNE): Questões

Desafiadoras e Embates Emblemáticos (1st ed.). Brasília: INEP, 2013.

REMY, M. A., QUEIROZ, S., FILHO, L. A. da S. Evolução Recente do Emprego Formal no Brasil: 2000-2008. Revista ABET, X(1), 57-78, 2011.

RESENDE, G. M., MOREIRA, P. G., ALVES, A. M., NETO, J. M. R. Brasil: Dez anos da Política Nacional de Desenvolvimento Regional (PNDR). Boletim Urbano, Regional e Ambiental: IPEA, 11, 29-35, 2015. 
ROWTHORN, R., RAMASWAMY, R. Growth, Trade and Deindustrialization. IMF Working Paper No. WP/98/60, New York, 1998.

SABOIA, J. A continuidade do processo de desconcentração regional da indústria brasileira nos anos 2000. Nova Economia, 23(2), 219-278, 2013.

SESSA, C. B., SIMONATO, T. C., DOMINGUES, E. P. O ciclo das Commodities e crescimento regional desigual no Brasil: uma aplicação de equilíbrio geral computável (EGC). Texto para Discussão N. 551, Universidade Federal de Minas Gerais, Belo Horizonte, 2017.

SESSO FILHO, U. A., RODRIGUES, R. L., MORETTO, A. C., BRENE, P. R. A., LOPES, R. Decomposição estrutural da variação do emprego no Brasil, 1991-2003. Economia Aplicada, 14(1), 99-123, 2010.

SILVEIRA NETO, R.; AZZONI, C. Os programas sociais e a recente queda na desigualdade regional da renda no Brasil. In CAMPELLO, T., NERI, M. (Orgs.). Bolsa Família: uma década de inclusão e cidadania. Brasilia: IPEA, pp 217-232, 2013.

SIMÕES, R. Métodos de Análise Regional e Urbana: diagnóstico aplicado ao planejamento. Texto para Discussão N. 259, Universidade Federal de Minas Gerais, Belo Horizonte, 2005.

Thiago Caliari. Doutor em Economia. Instituto Tecnológico de Aeronáutica (ITA). Professor Adjunto IV. Praça Marechal Eduardo Gomes, 50, Prédio IEF sala 220, Vila das Acácias, 12228-900 São José dos Campos/SP - Brasil. E-mail: caliari@ita.br.

Ulisses Pereira dos Santos. Doutor em Economia. Centro de Desenvolvimento e Planejamento Regional da Universidade Federal de Minas Gerais (Cedeplar/UFMG). Professor Adjunto I. Avenida Presidente Antônio Carlos, 6627, 31270-901 Belo Horizonte/MG - Brasil. E-mail: ulisses@cedeplar.ufmg.br

Como citar: CALIARI, Thiago; SANTOS, Ulisses Pereira. Evolução estrutural e setorial de emprego nas Microrregiões Brasileiras: uma Análise Exploratória para o período 2003-2013 pelo método shift-share. Redes (St. Cruz Sul, Online), Santa Cruz do Sul, v. 25, p. 2361-2384, 2020. ISSN 1982-6745. doi:https://doi.org/10.17058/redes.v25i0.14630. 
Evolução estrutural e setorial de emprego nas Microrregiões Brasileiras: uma Análise Exploratória para o período 2003-2013 pelo método shift-share

\section{CONTRIBUIÇÃO DE CADA AUTOR}

a. Fundamentação teórico-conceitual e problematização: Thiago Caliari e Ulisses Pereira dos Santos

b. Pesquisa de dados e análise estatística: Thiago Caliari

c. Elaboração de figuras e tabelas: Thiago Caliari

d. Fotos: não se aplica

e. Elaboração e redação do texto: Thiago Caliari e Ulisses Pereira dos Santos

f. Seleção das referências bibliográficas: Thiago Caliari e Ulisses Pereira dos Santos

Fontes de financiamento: não se aplica 